\title{
Plant oil-based shape memory polymer using acrylic monolith
}

\author{
T. Tsujimoto* ${ }^{*}$ E. Ohta, H. Uyama \\ Department of Applied Chemistry, Graduate School of Engineering, Osaka University, Yamadaoka 2-1, Suita, $565-0871$ \\ Osaka, Japan
}

Received 21 January 2015; accepted in revised form 15 March 2015

\begin{abstract}
This article deals with the synthesis of a plant oil-based material using acrylic monolith. An acrylic monolith bearing oxirane groups was prepared via simple technique that involved the dissolution of poly(glycidyl methacrylate-comethyl methacrylate) (PGMA) in ethanolic - aqueous solution by heating and subsequent cooling. The PGMA monolith had topologically porous structure, which was attributed to the phase separation of the polymer solution. The PGMA monolith was impregnated by epoxidized soybean oil (ESO) containing thermally-latent catalyst, and the subsequent curing produced a crosslinked material with relatively good transparency. The Young's modulus and the tensile strength of polyESO/PGMA increased compared with the ESO homopolymer. The strain at break of polyESO/PGMA was larger than that of the ESO homopolymer and crosslinked PGMA. Furthermore, polyESO/PGMA exhibited good shape memory-recovery behavior.
\end{abstract}

Keywords: polymer composites, renewable resource, epoxidized soybean oil, monolith, shape memory polymer

\section{Introduction}

The depletion of fossil fuel and the environmental issues of petroleum-based materials piqued large interest in renewable bio-based products synthesized from natural resources. The use of biomass to produce energy and chemicals is currently recommended for the reduction of fossil fuel utilization and carbon dioxide emissions involved in global warming. Furthermore, bio-based materials may offer the advantages of biodegradability in composting subsequent to their primary use [1, 2].

Plant oils, such as linseed, sunflower, soybean, and palm oils, are one of the cheapest and most abundant renewable resources, and their uses as starting materials offer numerous advantages, such as low toxicity and inherent biodegradability [3]. Triglyceride natural oils have been utilized extensively for coatings, inks, plasticizers, lubricants, resins and agrochemicals in addition to their applications in the food industry.
Most of plant oil-based polymeric materials, however, do not show the properties of rigidity and strength required for structural applications by themselves. Epoxidized plant oils are synthesized from common unsaturated plant oils, such as linseed, soybean, and palm oils, by standard epoxidation reaction. Epoxidized soybean oil (ESO) is commercially available, and has been used as plasticizers for poly(vinyl chloride), chlorinated rubber, and poly(vinyl alcohol) emulsion, and starting materials for polyurethane foam [4-7]. Furthermore, various polymerizations of epoxidized plant oils can be achieved by acid anhydrides, photoinitiators, latent catalysts, or acid catalysts. These epoxy compounds from renewable resources possess a high potential as a starting material for bio-based thermosetting plastics and coatings [8-10]. Epoxidized plant oils were cured in the presence of inorganic chemicals to produce organic-inorganic hybrid materials [11-13]. Recently,

\footnotetext{
${ }^{*}$ Corresponding author, e-mail: tsujimoto@chem.eng.osaka-u.ac.jp (C) BME-PT
} 
a green composite was prepared by the curing of ESO in the presence of porous poly(3-hydroxybutyrate). The porous structure of poly(3-hydroxybutyrate) improved the mechanical properties of the ESObased network polymer [14].

Shape memory materials have a sensitive response to external stimuli, such as temperature, light, $\mathrm{pH}$, humidity, chemicals, and electricity. In recent years, shape memory polymers have received increasing attention because of their good processability, low cost, and high recovery ability, and have been used in various fields [15-25]. Thermally triggered shape memory polymer is first processed to receive a permanent shape. Above a given temperature range (switching temperature), shape memory polymer can be deformed into a temporary shape that is fixed by cooling under external stress. When the sample is reheated above the switching temperature, the permanent shape is recovered. Although bio-based shape memory polymers including poly (lactic acid) and polyglycolid were developed, most of them were block polymers prepared by a two-stage synthesis or coupling method.

A monolith is defined as a block structured material which consists of continuous substructures of regular or irregular channels [26]. Owing to the exciting properties including high specific surface area, high permeability, low density, and fast mass transfer performance, monoliths have received a considerable amount of attention in various fields [27-31]. Polymer monolithic materials are often prepared by the copolymerization of a monomer and a crosslinker in the presence of a porogen. In this case, the pore in the polymer monolith is fabricated as aggregation of polymer grains formed though an abrupt increase of molecular weight during polymerization. The resultant porous structure is disordered in shape, and it is accompanied by difficulties in the precise control of the porous structural parameters such as pore and skeleton size. Recently, we have reported the fabrication of polymer monolith by thermally induced phase separation (TIPS) $[32,33]$. This method is an excellent way to prepare microcellular foams and membranes with controlled morphologies. In this study, an acrylic polymer monolith containing oxirane groups was fabricated by TIPS and used as a reinforcement material for the ESO polymer. The resulting material showed relatively good transparency with improvements in the mechanical properties. Furthermore, the shape mem- ory properties of the resulting material were investigated.

\section{Experimental}

\subsection{Materials}

ESO and a thermally-latent cationic catalyst (benzylsulfonium hexafluoroantimonate derivative, commercial name: Sun-Aid SI-60L) were gifts from Mizutani Paint Co., (Osaka, Japan) and Sanshin Chemical Industry Co. (Yamaguchi, Japan), respectively. The number of oxirane groups of ESO was 3.7 per a molecule, determined by nuclear magnetic resonance $\left({ }^{1} \mathrm{H}\right.$ NMR). Poly(glycidyl methacrylateco-methyl methacrylate) (PGMA) was synthesized by common radical polymerization by using azobisisobutyronitrile as an initiator. The molecular weight of PGMA was determined by size exclusion chromatography (SEC) $\left(M_{\mathrm{w}}=1.9 \times 10^{5}, M_{\mathrm{w}} / M_{\mathrm{n}}=3.2\right)$. The molar ratio of glycidyl methacrylate unit determined by ${ }^{1} \mathrm{H}$ NMR was $20 \%$. Other reagents and solvents were commercially available and used as received.

\subsection{Fabrication of PGMA monolith}

The following was a procedure for the fabrication of PGMA monolith. PGMA powder $(160 \mathrm{mg})$ was dissolved in a mixture of ethanol and water $(2 \mathrm{~mL}$, $80 / 20 \mathrm{vol} \%$ ) at $80^{\circ} \mathrm{C}$ for $15 \mathrm{~min}$, and the solution was then cooled at $20^{\circ} \mathrm{C}$. After $2 \mathrm{~h}$, the resulting white solid was washed with ethanol several times to obtain a PGMA monolith.

\subsection{Synthesis of polyESO/PGMA}

The synthesis procedure of polyESO/PGMA was carried out as follows. PGMA monolith was immersed in ESO containing thermally-latent catalyst, followed by the removal of residual ethanol under reduced pressure (ca. $800 \mathrm{~Pa}$ ) at room temperature. Then, the sample was heated at $110^{\circ} \mathrm{C}$ for $2 \mathrm{~h}$ under a pressure of $5 \mathrm{MPa}$ by using a hot-pressing machine (C180, Imoto Machinery Co., Kyoto, Japan) to produce a polyESO/PGMA. The ESO homopolymer and the crosslinked PGMA were synthesized by using thermally-latent catalyst at $110^{\circ} \mathrm{C}$ for $2 \mathrm{~h}$.

\subsection{Investigation of shape memory-recovery behaviors of polyESO/PGMA}

The polyESO/PGMA in strip form was prepared as a permanent shape, and was deformed to the spiral form by wrapping around a Teflon rod at $130^{\circ} \mathrm{C}$. 
The temporary shape of the polyESO/PGMA was fixed by the subsequent cooling to room temperature. Upon reheating at $130^{\circ} \mathrm{C}$, the deformed shape was restored to its original shape.

\subsection{Measurements}

${ }^{1} \mathrm{H}$ NMR spectrum was recorded on a DPX-400 instrument (Bruker Biospin Co., MA, USA). SEC analysis was carried out by using a SC8020 apparatus (Tosoh, Tokyo, Japan) with a refractive index detector at $40^{\circ} \mathrm{C}$ under the following conditions: TOSOH TSKgel G4000 column and chloroform eluent at a flow rate of $1.0 \mathrm{~mL} \cdot \mathrm{min}^{-1}$. The calibration curve was obtained using polystyrene standards. Fourier-transform infrared spectroscopy (FT-IR) was measured by a Spectrum One (Perkin-Elmer Inc., MA, USA) (4 scans). Scanning electron microscopic (SEM) analysis was carried out by using a SU-3500 instrument (Hitachi High-Technologies Co., Tokyo, Japan). Dynamic viscoelasticity analysis (DMA) controlling strain/amplitude was performed by using a DMS6100 (Hitachi High-Tech Science Co., Tokyo, Japan) with a frequency of $1 \mathrm{~Hz}$ at a heating rate of $3^{\circ} \mathrm{C} \cdot \mathrm{min}^{-1}$. Tensile properties were measured by a EZ Graph (Shimadzu Co., Kyoto, Japan) with a crosshead speed of $5 \mathrm{~mm} \cdot \mathrm{min}^{-1}$. The sample was cut into a plate shape of $20 \mathrm{~mm} \times 10 \mathrm{~mm} \times 0.1 \mathrm{~mm}$.

\section{Results and discussion}

\subsection{Synthesis of polyESO/PGMA}

In general, water and lower aliphatic alcohols are regarded as non-solvents or poor solvents for acrylic polymers including poly(methyl methacrylate)
(PMMA) and its derivatives. However, acrylic polymers are dissolved in a mixture of aliphatic alcohol and water by heating, this phenomenon is called pseudo-classical cosolvent system [34]. Recently, we have developed a new fabrication technique of acrylic monoliths by TIPS using temperature dependence of solubility for the cosolvent. PGMA powder was dissolved in a mixture of ethanol and water $(80 / 20 \mathrm{vol} \%)$ at $60^{\circ} \mathrm{C}$, and the solution was then allowed to cool at room temperature to yield a white monolithic material retaining the shape of vessel. The general procedure is illustrated in Figure 1.

The morphology of the resulting PGMA monolith was homogeneous macroporous with three-dimensional interconnected fibrous structure (Figure 2). In the process, a homogeneous polymer solution was cooled below the binodal line, and the Gibbs free energy of the system increased, which consequently resulted in phase separation. The phase separation continued until the combination of two phases reached stable condition with lowest energy. In other words, the solution separated into a polymer-rich phase and a polymer-lean phase, and the polymerrich phase became immobilized by gelation and vitrification.

In this study, the PGMA monolith was used as a reinforcement material for the ESO polymer. A polyESO/PGMA was prepared by an immersion method. This method relies on the penetration of ESO into the PGMA monolith. The PGMA monolith was immersed in ESO containing thermally-latent catalyst, followed by vacuum treatment to remove the residue ethanol.

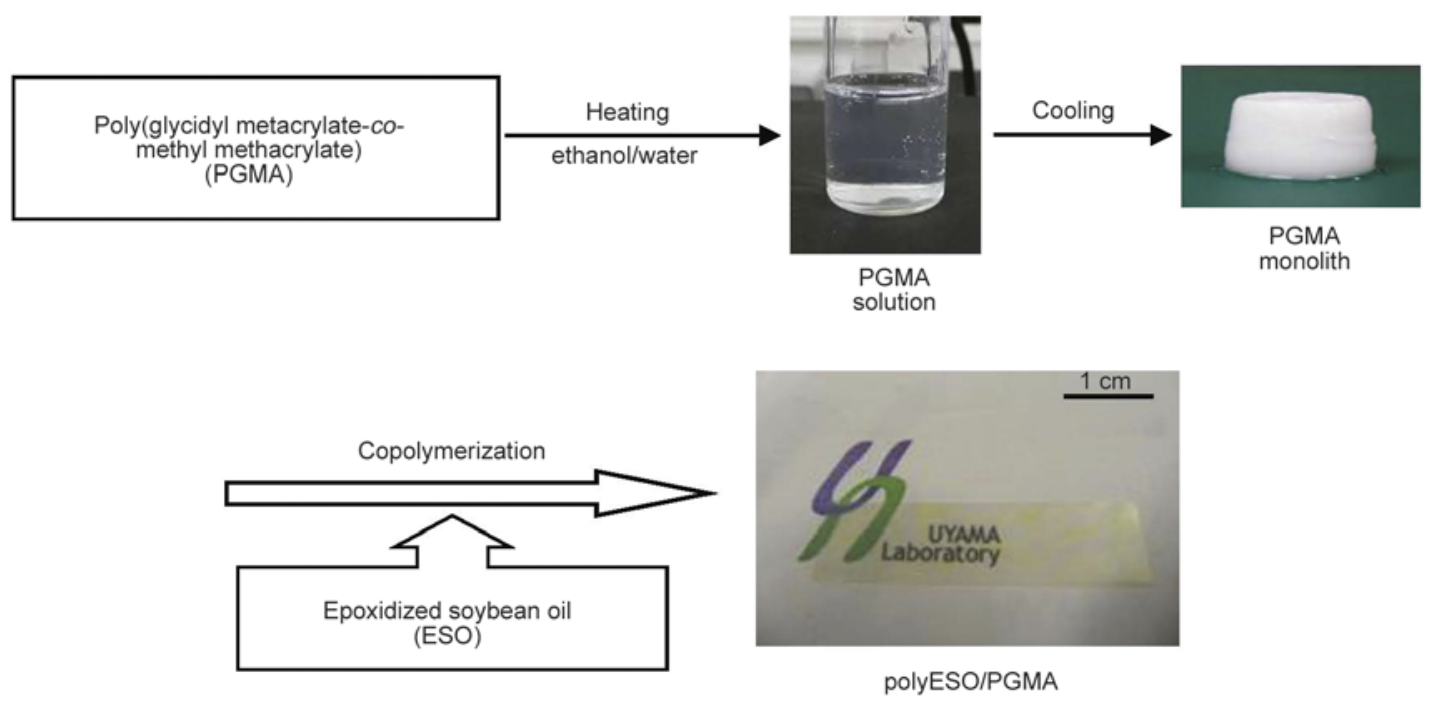

Figure 1. General procedure for preparation of PGMA monolith and polyESO/PGMA 


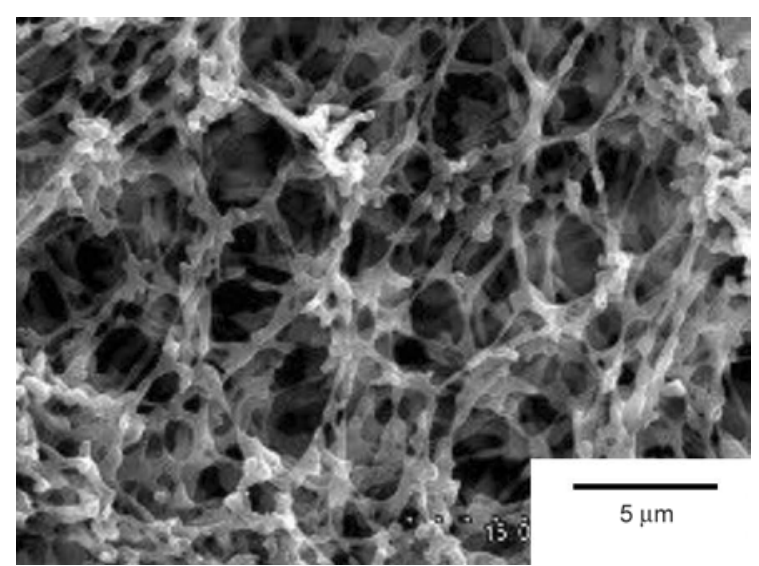

Figure 2. SEM image of PGMA monolith

Then, crosslinking reaction was carried out at $110^{\circ} \mathrm{C}$ to yield a polyESO/PGMA. The resulting material was insoluble in any organic solvent. The ratio of ESO component, determined by weight change, was $50 \mathrm{wt} \%$. During the reaction, the oxirane groups of ESO and PGMA reacted with each other. The polyESO/PGMA showed relatively high transparency, and the transmittance at $700 \mathrm{~nm}$ was more than $75 \%$. On the other hand, the blend of ESO and PGMA prepared by solvent casting was opaque due to the immiscibility of PGMA with ESO. These data suggest that the porous structure of the monolith was retained without shrinkage and that the pore of the PGMA monolith was filled by ESO component.

In the FT-IR spectrum of the polyESO/PGMA, characteristic peaks at ca. $840 \mathrm{~cm}^{-1}$, ascribed to the $\mathrm{C}-\mathrm{C}$ antisymmetric stretching of the oxirane groups of ESO and PGMA, disappeared, and a broad peak centered at $3400 \mathrm{~cm}^{-1}$, ascribed to the $\mathrm{O}-\mathrm{H}$ stretching, was observed. These results indicate that the oxirane groups of ESO and PGMA are consumed to form hydroxyl-terminated network polymer.

\subsection{Thermal and mechanical properties of polyESO/PGMA}

In order to evaluate the effect of the incorporation of PGMA monolith, dynamic viscoelasticity analysis as a function of temperature was performed. The storage modulus and loss factor of the ESO homopolymer, the crosslinked PGMA, and the polyESO/ PGMA are shown in Figure 3. In the ESO homopolymer, a rapid decrease of storage modulus was observed at $-25^{\circ} \mathrm{C}$. The storage modulus of the crosslinked PGMA also decreased remarkably at $120^{\circ} \mathrm{C}$, due to low crosslinking density. On the other hand, it can be found that the storage modulus of polyESO/PGMA drops stepwise, which is attrib-
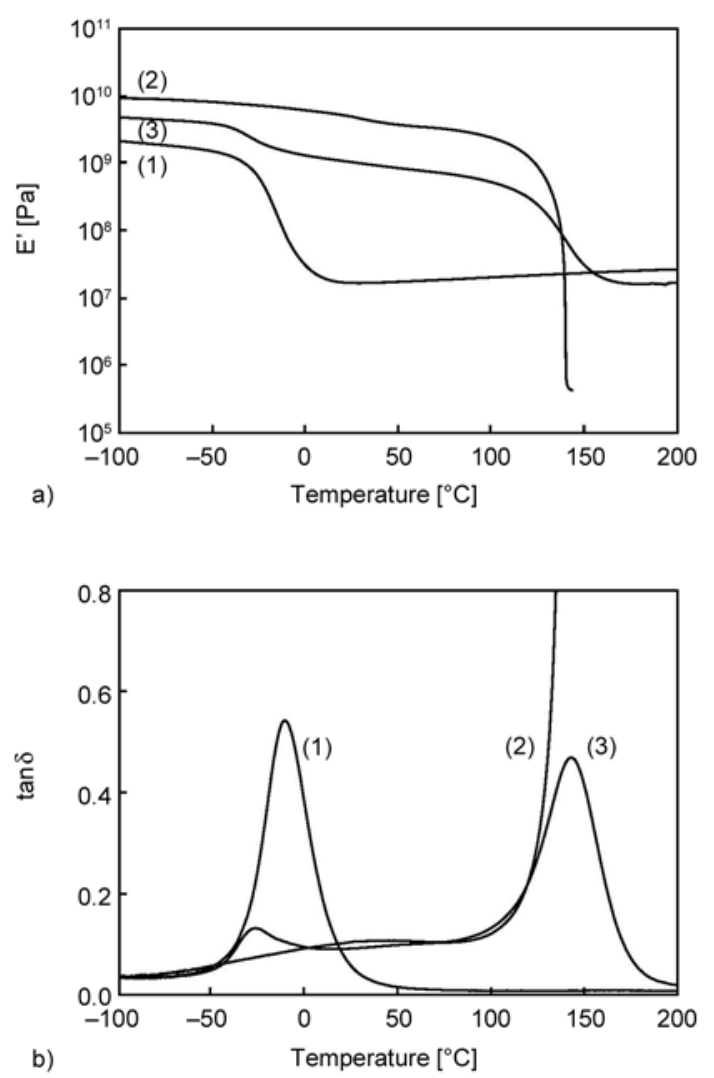

Figure 3. Dynamic viscoelasticity of (1) ESO homopolymer, (2) crosslinked PGMA, and (3) polyESO/ PGMA; (a) storage modulus, (b) loss factor

uted to the glass transitions of ESO polymer and PGMA. This result indicates that ESO polymer and the PGMA monolith are immiscible. At lower temperature, the polyESO/PGMA was glassy with a storage modulus of about $4.0 \mathrm{GPa}$, and the storage modulus dropped at $-25^{\circ} \mathrm{C}$, giving rise to the first rubbery state. Upon further heating, the storage modulus dropped again at $120^{\circ} \mathrm{C}$ to yield the second rubbery state. In second rubbery state, the storage modulus of polyESO/PGMA was about $16 \mathrm{MPa}$ which is higher than that of the crosslinked PGMA, indicating that the oxirane groups of ESO and PGMA react with each other to form the network structure. Figure 4 shows the stress-strain curves of the ESO homopolymer, the crosslinked PGMA, and the polyESO/PGMA. The Young's modulus and the tensile strength of the polyESO/PGMA were larger than those of the ESO homopolymer. These behaviors are related to the three-dimensional porous structure of the PGMA monolith, suggesting that the PGMA monolith effectively reinforces ESO polymer. The ESO homopolymer and the crosslinked PGMA fractured at 14 and $8 \%$, respectively. On the other hand, the polyESO/PGMA was improved in brittleness, 


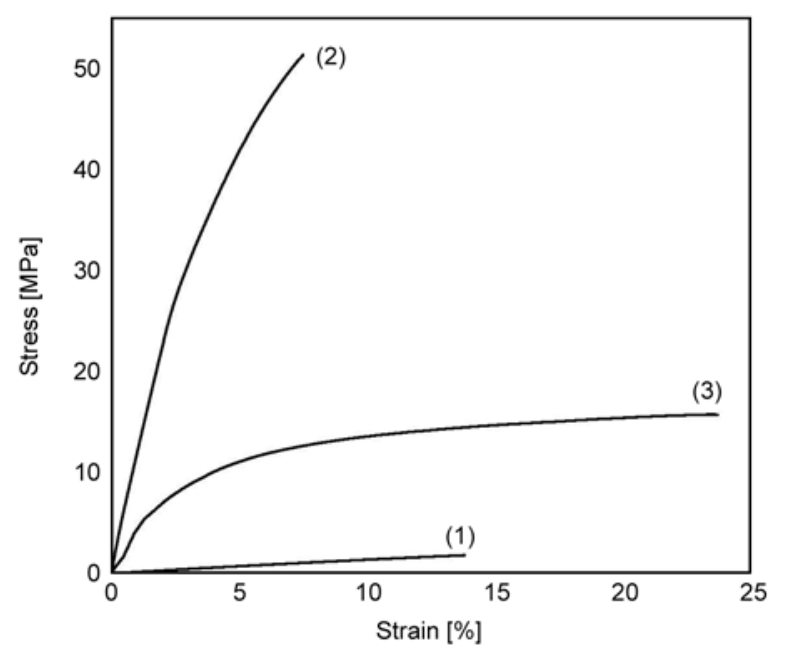

Figure 4. Stress-strain curves of (1) ESO homopolymer, (2) crosslinked PGMA, and (3) polyESO/PGMA

and the strain at break of the polyESO/PGMA was $24 \%$.

\subsection{Shape memory-recovery behaviors of polyESO/PGMA}

The shape memory-recovery behaviors of the polyESO/PGMA are demonstrated in Figure 5. In this study, the shape memory-recovery behaviors were activated by the glass transition of PGMA component as a switching temperature. The polyESO/PGMA was easily deformed above the glass transition temperature of PGMA component. The ESO homopolymer could not be deformed because of the brittleness. The temporary shape of the polyESO/PGMA was fixed by the subsequent cooling to room temperature. Upon reheating above the glass transition temperature of PGMA component, the deformed shape was recovered to its original shape. On the other hand, the shape of the crosslinked PGMA was not returned to the original shape. Furthermore, the shape memory-recovery behaviors of the polyESO/PGMA were repeatable. The plausible shape memory-recovery mechanism is as follows. The driving force of shape recovery is the elastic force of ESO polymer generated during the deformation. Above the switching temperature, PGMA component is in rubbery state and the sample is easily deformed. After the subsequent cooling, PGMA component becomes glassy and the temporary shape is fixed with the internal stress of ESO polymer. Upon reheating above the switching temperature, the mobility of PGMA chains becomes larger, and the shape of the sample returns to the original shape by the entropy elasticity of ESO polymer.

\section{Conclusions}

In this study, an acrylic monolith bearing oxirane groups was fabricated via thermally induced phase separation in ethanol aqueous solution. The resulting PGMA monolith was a piece of white material with three-dimensional interconnected porous structure. The PGMA monolith was immersed in ESO containing thermally-latent catalyst under vacuum condition, and the subsequent crosslinking reaction produced polyESO/PGMA with relatively good transparency. The DMA result of the polyESO/PGMA showed two glass transitions, due to the immiscibility of PGMA with ESO. The Young's modulus and the tensile strength of the polyESO/PGMA were larger than those of the ESO homopolymer. The incorporation of the PGMA monolith also increased the strain at break, indicating that the resulting material is effectively reinforced without sacrificing toughness. Furthermore, the polyESO/PGMA exhibited excellent shape memory property.
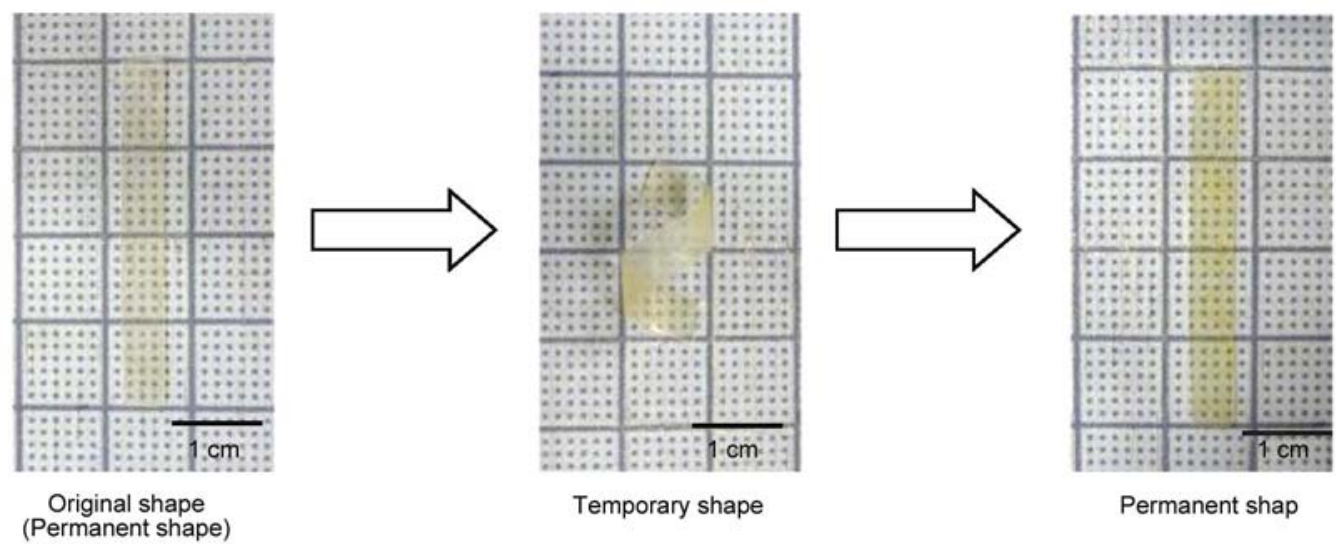

Figure 5. Shape memory-recovery behaviors for polyESO/PGMA 


\section{Acknowledgements}

This study supported by a Grant-in-Aid for Young Scientists from Japan Society for the Promotion of Science (JSPS) (No. 268101140).

\section{References}

[1] Ragauskas A. J., Williams C. K., Davison B. H., Britovsek G., Cairney J., Eckert C. A., Frederick Jr. W. J., Hallett J. P., Leak D. J., Liotta C. L., Mielenz J. R., Murphy R., Templer R., Tschaplinski T.: The path forward for biofuels and biomaterials. Science, 311, 484489 (2006).

DOI: $10.1126 /$ science. 1114736

[2] Nagarajan V., Mohanty A. K., Misra M.: Sustainable green composites: Value addition to agricultural residues and perennial grasses. ACS Sustainable Chemisry and Engineering, 1, 325-333 (2013).

DOI: $10.1021 / \mathrm{sc} 300084 \mathrm{z}$

[3] Quirino R. L., Garrison T. F., Kessler M. R.: Matrices from vegetable oils, cashew nut shell liquid, and other relevant systems for biocomposite applications. Green Chemistry, 16, 1700-1715 (2014).

DOI: $10.1039 / \mathrm{c} 3 \mathrm{gc} 41811 \mathrm{a}$

[4] Swern D., Billen G. N., Findley T. W., Scanlan J. T.: Hydroxylation of monounsaturated fatty materials with hydrogen peroxide. Journal of the American Chemical Society, 67, 1786-1789 (1945).

DOI: $10.1021 / \mathrm{ja} 01226 \mathrm{a} 050$

[5] Petrović Z. S., Zhang W., Javni I.: Structure and properties of polyurethanes prepared from triglyceride polyols by ozonolysis. Biomacromolecules, 6, 713719 (2005).

DOI: $10.1021 / \mathrm{bm} 049451 \mathrm{~s}$

[6] Biresaw G., Liu Z. S., Erhan S. Z.: Investigation of the surface properties of polymeric soaps obtained by ringopening polymerization of epoxidized soybean oil. Journal of Applied Polymer Science, 108, 1976-1985 (2008).

DOI: $10.1002 / a p p .27784$

[7] Saithai P., Lecomte J., Dubreucq E., Tanrattanakul V.: Effects of different epoxidation methods of soybean oil on the characteristics of acrylated epoxidized soybean oil-co-poly(methyl methacrylate) copolymer. Express Polymer Letters, 7, 910-924 (2013).

DOI: 10.3144/expresspolymlett.2013.89

[8] Chakrapani S., Crivello J. V.: Synthesis and photoinitiated cationic polymerization of epoxidized castor oil and its derivatives. Journal of Macromolecular Science Part A: Pure and Applied Chemistry, 35, 1-20 (1998). DOI: $10.1080 / 10601329808001959$

[9] Tran P., Graiver D., Narayan R.: Biocomposites synthesized from chemically modified soy oil and biofibers. Journal of Applied Polymer Science, 102, 69-75 (2006). DOI: $10.1002 /$ app.22265
[10] Wang R., Schuman T. P.: Vegetable oil-derived epoxy monomers and polymer blends: A comparative study with review. Express Polymer Letters, 7, 272-292 (2013).

DOI: $10.3144 /$ expresspolymlett.2013.25

[11] Tsujimoto T., Uyama H., Kobayashi S.: Green nanocomposites from renewable resources: Biodegradable plant oil-silica hybrid coatings. Macromolecular Rapid Communications, 24, 711-714 (2003). DOI: $10.1002 /$ marc.200350015

[12] Miyagawa H., Misra M., Drzal L. T. Mohanty A. K.: Novel biobased nanocomposites from functionalized vegetable oil and organically-modified layered silicate clay. Polymer, 46, 445-453 (2005). DOI: $10.1016 /$ j.polymer.2004.11.031

[13] Lligadas G., Ronda J. C., Galià M., Cádiz V.: Bionanocomposites from renewable resources: Epoxidized linseed oil-polyhedral oligomeric silsesquioxanes hybrid materials. Biomacromolecules, 7, 3521-3526 (2006). DOI: 10.1021/bm060703u

[14] Hosoda N., Tsujimoto T., Uyama H.: Plant oil-based green composite using porous poly(3-hydroxybutyrate). Polymer Journal, 46, 301-306 (2014).

DOI: $10.1038 /$ pj.2014.1

[15] Feninat F. E., Laroche G., Fiset M., Mantovani D.: Shape memory materials for biomedical applications. Advanced Engineering Materials, 4, 91-104 (2002). DOI: $10.1002 / 1527-2648(200203) 4: 3<91:: A I D-$ ADEM91>3.0.CO;2-B

[16] Yamashiro M., Inoue K., Iji M.: Recyclable shapememory and mechanical strength of poly(lactic acid) compounds cross-linked by thermo-reversible DielsAlder reaction. Polymer Journal, 40, 657-662 (2008). DOI: $10.1295 /$ polymj.PJ2008042

[17] Kolesov I. S., Radusch H-J.: Multiple shape-memory behavior and thermal-mechanical properties of peroxide cross-linked blends of linear and short-chain branched polyethylenes. Express Polymer Letters, 2, 461-473 (2008).

DOI: $10.3144 /$ expresspolymlett.2008.56

[18] Luo X., Mather P. T.: Triple-shape polymeric composites (TSPCs). Advanced Functional Materials, 20, 2649-2656 (2010).

DOI: $10.1002 / \mathrm{adfm} .201000052$

[19] Guo B., Chen Y., Lei Y., Zhang L., Zhou W. Y., Rabie A. B. M., Zhao J.: Biobased poly(propylene sebacate) as shape memory polymer with tunable switching temperature for potential biomedical applications. Biomacromolecules, 12, 1312-1321 (2011). DOI: $10.1021 / \mathrm{bm} 2000378$

[20] Ratna D., Karger-Kocsis J.: Shape memory polymer system of semi-interpenetrating network structure composed of crosslinked poly (methyl methacrylate) and poly(ethylene oxide). Polymer, 52, 1063-1070 (2011). DOI: $10.1016 /$ j.polymer.2010.12.054 
[21] Julich-Gruner K. K., Löwenberg C., Neffe A. T., Behl M., Lendlein A.: Recent trends in the chemistry of shape-memory polymers. Macromolecular Chemistry and Physics, 214, 527-536 (2013).

DOI: $10.1002 /$ macp.201200607

[22] Fejős M., Molnár K., Karger-Kocsis J.: Epoxy/polycaprolactone systems with triple-shape memory effect: Electrospun nanoweb with and without graphene versus co-continuous morphology. Materials, 6, 4489-4504 (2013). DOI: $10.3390 / \mathrm{ma} 6104489$

[23] Tsujimoto T., Uyama H.: Full biobased polymeric material from plant oil and poly(lactic acid) with a shape memory property. ACS Sustainable Chemisry and Engineering, 2, 2057-2062 (2014).

DOI: $10.1021 / \mathrm{sc} 500310 \mathrm{~s}$

[24] Tsujimoto T., Toshimitsu K., Uyama H., Takeno S., Nakazawa Y.: Maleated trans-1,4-polyisoprene from Eucommia ulmoides Oliver with dynamic network structure and its shape memory property. Polymer, 55, 64886493 (2014).

DOI: $10.1016 /$ j.polymer.2014.10.035

[25] Karger-Kocsis J. Kéki S.: Biodegradable polyesterbased shape memory polymers: Concepts of (supra) molecular architecturing. Express Polymer Letters, 8, 397-412 (2014).

DOI: $10.3144 /$ expresspolymlett.2014.44

[26] Ceylan S., Kirschning A.: Organic synthesis with mini flow reactors using immobilised catalysts. in 'Recoverable and recyclable catalysts' (ed.: Benaglia M.) Wiley, New York, 379-410 (2009).

[27] Hüsing N., Schubert U.: Aerogels-airy materials: Chemistry, structure, and properties. Angewandte Chemie International Edition, 37, 22-45 (1998).

DOI: $10.1002 /($ SICI $1521-3773(19980202) 37: 1 / 2<22$ $\because$ AID-ANIE22>3.0.CO;2-I
[28] Mayr M., Mayr B., Buchmeiser M. R.: Monolithic materials: New high-performance supports for permanently immobilized metathesis catalysts. Angewante Chemie International Edition, 40, 3839-3842 (2001). DOI: 10.1002/1521-3773(20011015)40:20<3839::AIDANIE3839>3.0.CO;2-O

[29] Hosoda N., Tsujimoto T. Uyama H.: Green composite of poly(3-hydroxybutyrate-co-3-hydroxyhexanoate) reinforced with porous cellulose. ACS Sustainable Chemisry and Engineering, 2, 248-253 (2014). DOI: $10.1021 / \mathrm{sc} 400290 \mathrm{y}$

[30] Wang H., Zhang H., Lv Y., Svec F., Tan T.: Polymer monoliths with chelating functionalities for solid phase extraction of metal ions from water. Journal of Chromatography A, 1343, 128-134 (2014). DOI: $10.1016 /$ j.chroma.2014.03.072

[31] Hasegawa G., Kanamori K., Nakanishi K., Yamago S.: Fabrication of highly crosslinked methacrylate-based polymer monoliths with well-defined macropores via living radical polymerization. Polymer, 52, 46444647 (2011). DOI: $10.1016 /$ j.polymer.2011.08.028

[32] Okada K., Nandi M., Maruyama J., Oka T., Tsujimoto T., Kondoh K., Uyama H.: Fabrication of mesoporous polymer monolith: A template-free approach. Chemical Communications, 47, 7422-7424 (2011). DOI: $10.1039 / \mathrm{c} 1 \mathrm{cc} 12402 \mathrm{a}$

[33] Yoneda S., Han W., Hasegawa U., Uyama H.: Facile fabrication of poly(methyl methacrylate) monolith via thermally induced phase separation by utilizing unique cosolvency. Polymer, 55, 3212-3216 (2014).

DOI: 10.1016/j.polymer.2014.05.031

[34] Cowie J. M. G., Mohsin M. A., MacEwen I. J.: Alcoholwater cosolvent systems for poly(methyl methacrylate). Polymer, 28, 1569-1572 (1987). DOI: $10.1016 / 0032-3861(87) 90360-0$ 